\title{
PROJETO E IMPLANTAÇÃO DE UNIDADE PILOTO PARA PRODUÇÃO DE NANOPARTÍCULAS UTILIZANDO A TECNOLOGIA ANTISOLVENTE SUPERCRÍTICO (SAS)
}

\author{
P. S. SCHEIN, E. CASSEL, G. E. ROSSA e J. J. B. SILVA FILHO \\ Pontifícia Universidade Católica do Rio Grande do Sul, Faculdade de Engenharia \\ E-mail para contato: pedro.schein@acad.pucrs.br
}

\begin{abstract}
RESUMO - A produção de micro/nanopartículas tem atraído interesse de inúmeras pesquisas, uma vez que o desenvolvimento tecnológico possibilitou a produção e manipulação das mesmas, tendo aplicação em diversas áreas, como pigmentos, polímeros, fármacos e supercondutores. $\mathrm{O}$ uso de antissolvente supercrítico (SAS) para precipitação de micro/nanopartículas destaca-se dentre outras técnicas tradicionais, tais como spray drying e jet milling, visto que possibilita a obtenção de partículas com uma distribuição granulométrica mais homogênea e com menores dimensões. Neste contexto, este trabalho tem como objetivo projetar e implantar uma unidade piloto experimental de precipitação de partículas SAS acoplada a uma unidade de extração supercrítica. A execução do projeto iniciou com a elaboração do fluxograma de processo SAS e, utilizando o software solidworks ${ }^{\circledR}$, foi realizado um modelo tridimensional da unidade. Os componentes necessários para implantação e montagem do equipamento foram dimensionados e adquiridos. Para validação do mesmo, partículas de cafeína foram produzidas para analisar a sua capacidade de reprodutibilidade de resultados encontrados na literatura. As partículas obtidas dos ensaios de validação foram analisadas quanto à morfologia e dimensão através de imagens obtidas por um microscópio eletrônico de varredura.
\end{abstract}

\section{INTRODUÇÃO}

Governos, pesquisadores e indústrias tem demonstrado interesse na nanotecnologia, uma vez que esta possui ampla área de aplicação, tais como pigmentos, polímeros, fármacos e supercondutores. Conforme a tecnologia tem avançado, ampliou-se a possibilidade de produção e manipulação de micro/nanopartículas. Segundo dados da Agência Brasileira de Desenvolvimento Industrial (ABDI), a previsão para o mercado global nesta área, no que diz respeito à produção e à comercialização de produtos e equipamentos, não deve ser inferior a um trilhão de dólares em 2015 (ABDI, 2011).

O processo SAS se resume na recristalização do soluto de interesse pela supersaturação gerada no processo difusivo ocorrido quando o fluido supercrítico entra em contato com a solução orgânica (Careno et al, 2012). A força motriz para que ocorra a recristalização das partículas é a supersaturação, assim, o favorecimento dessa condição conduz a formação de um maior número de núcleos e menores partículas por unidade de tempo. A expansão causada pela difusão do fluido supercrítico na solução reduz a solubilidade do soluto devido à 
diminuição da densidade, enquanto a difusão do solvente em meio supercrítico proporciona a concentração do soluto (Bristow et al., 2001; Tai e Cheng, 1998).

Este trabalho teve por objetivo construir um equipamento de precipitação de nanopartículas utilizando antissolvente supercrítico (SAS) em escala piloto, acoplado à unidade de extração supercrítica. Sendo assim, o escopo deste foi dimensionar, projetar, adquirir e montar os equipamentos necessários para implantação da unidade SAS, utilizando alguns equipamentos da unidade piloto de extração supercrítica (Cassel et al., 2011). Também foram realizados ensaios de validação do equipamento em questão, visando verificar a sua estabilidade frente à operação em diferentes condições de processo e sua segurança. As partículas resultantes dos ensaios de validação foram analisadas quanto à aglomeração, dimensão e morfologia através de imagens obtidas por um microscópio eletrônico de varredura (MEV).

\section{MATERIAIS E MÉTODOS}

Para desenvolver a unidade de precipitação de micro/nanopartículas SAS, seguiu-se as etapas apresentadas no diagrama da Figura 1.

Figura 1 - Etapas do projeto e implantação da unidade de precipitação de partículas SAS

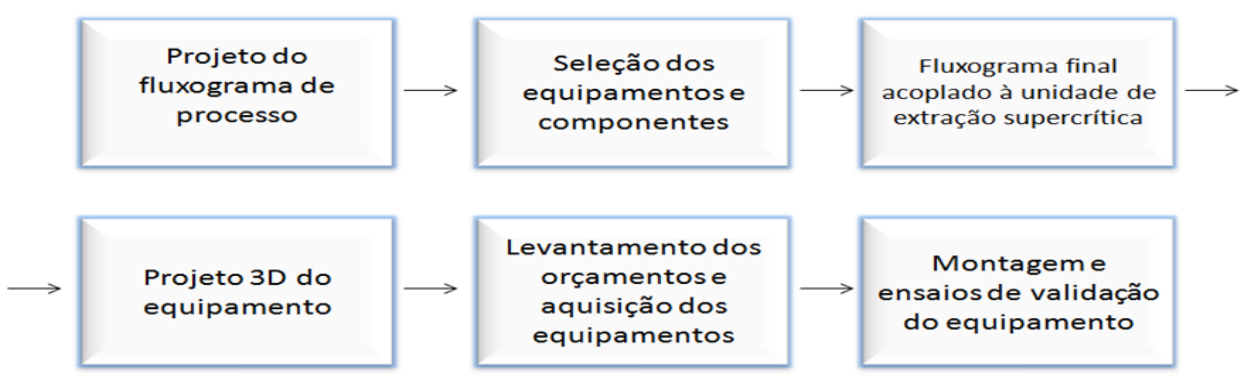

\subsection{Definição Teórica do Fluxograma de Processo}

A primeira etapa consistiu em desenvolver um fluxograma de processo para metodologia SAS, visando contemplar os principais componentes exigidos pelo novo processo. Em seguida, definiram-se quais seriam, entre os componentes necessários, aqueles que já constavam da unidade de extração supercrítica. A etapa final associada à definição teórica do fluxograma consistiu em distribuir os novos equipamentos exigidos pelo SAS no espaço delimitado pela unidade de extração supercrítica.

Partindo do fluxograma da unidade piloto de extração supercrítica, foi elaborado um novo fluxograma com as devidas modificações para implantação da metodologia SAS. O software Solidworks ${ }^{\circledR}$ foi utilizado para elaboração do projeto 3D da unidade de precipitação de partículas. A finalidade foi estabelecer a melhor configuração dos equipamentos necessários para implantação do processo SAS no espaço físico disponível na unidade de extração supercrítica, além de possibilitar o dimensionamento das tubulações e a quantificação das conexões. Dispositivos de segurança associados a possíveis aumentos 
excessivos de pressão tais como alarmes, discos de ruptura e válvulas de seguranças e alívio também foram previstos, visto que o processo opera a pressões elevadas.

\subsection{Seleção dos Equipamentos e Componentes}

Nesta etapa do projeto foram definidos os equipamentos e componentes necessários para a montagem do equipamento. É importante salientar que o equipamento foi projeto para fins de pesquisa, privilegiado a flexibilidade quanto às condições operacionais e quanto aos tipos de solventes utilizados. Por isso, ao contrário das unidades industriais, o sistema desenvolvido não possui uma especificação ótima de projeto, pois não opera em condições padrões. Outro fator importante levando em consideração foi o material de construção dos componentes e equipamento, visto que a unidade SAS tem que suportar alta pressão e solventes orgânicos. Dimensionados e definidos os equipamentos do processo estes foram orçados e adquiridos, priorizando o uso aproveitando de componentes já contemplados na unidade piloto de extração supercrítica. A meta sempre foi construir uma unidade híbrida de extração supercrítica e de precipitação de partículas.

\subsection{Ensaios de Validação}

Para verificar se o equipamento atendia as exigências de estabilidade, veracidade das variáveis de processo e reprodutibilidade foram realizados ensaios de validação. Inicio-se com a calibração dos sensores de temperatura, pressão e vazão, assim como a avaliação do funcionamento das bombas. Para verificar eventuais vazamentos foram realizados ensaios operacionais estanqueidade. A etapa seguinte foi reproduzir os resultados obtidos por Brun et al. (2012) para a cafeína.

Cafeína $(<99 \%)$ foi dissolvida em diclorometano na concentração de $0,054 \mathrm{~g} / \mathrm{mL}$. As condições do processo foram as seguintes: $\mathrm{P}=100$ bar (pressão do vaso de precipitação), $\mathrm{T}=60^{\circ} \mathrm{C}$ (temperatura do vaso de precipitação), $\mathrm{V}_{1}=4 \mathrm{~mL} / \mathrm{min}$ (vazão da solução de cafeína em diclorometano), $\mathrm{V}_{2}=1,0 \mathrm{~kg} / \mathrm{h}$ (vazão do antissolvente supercrítico $\mathrm{CO}_{2}$ ). Os experimentos foram realizados em duplicata.

Análise da morfologia e da dimensão das partículas obtidas: As partículas obtidas em cada condição operacional foram analisadas quanto à morfologia, aglomeração e dimensão através de imagens obtidas pelo microscópio eletrônico de varredura (Philips, modelo XL30). As imagens foram geradas a partir de amostras depositadas em um stub coberto por fita dupla face de carbono com superfície metalizada com ouro.

\section{RESULTADOS E DISCUSSÕES}

\subsection{Fluxograma da unidade piloto híbrida extração supercrítica - precipitação de partículas SAS}

O fluxograma proposto para implantação da unidade piloto híbrida extração supercrítica/precipitação de partícula SAS é apresentado na Figura 2, onde a parte modificada 
da unidade é apresentada na cor vermelha. Vale salientar que para fins didáticos as dimensões dos componentes não estão respeitando as dimensões originais.

Entre os equipamentos e componentes presentes na unidade piloto de extração supercrítica (Cassel et al., 2011) e que foram utilizados pelos dois processos destacam-se: trocador de calor para arrefecimento do $\mathrm{CO}_{2}$; bomba de $\mathrm{CO}_{2}$; trocador de calor para aquecimento do $\mathrm{CO}_{2}$; bomba de solução; sensor de vazão; recipiente da solução líquida (solvente orgânico + soluto); controle de temperatura da válvula micrométrica; válvula de segurança e alivio; tubulações e frasco de separação.

Figura 2 - Fluxograma da unidade piloto híbrida extração supercrítica/processo SAS

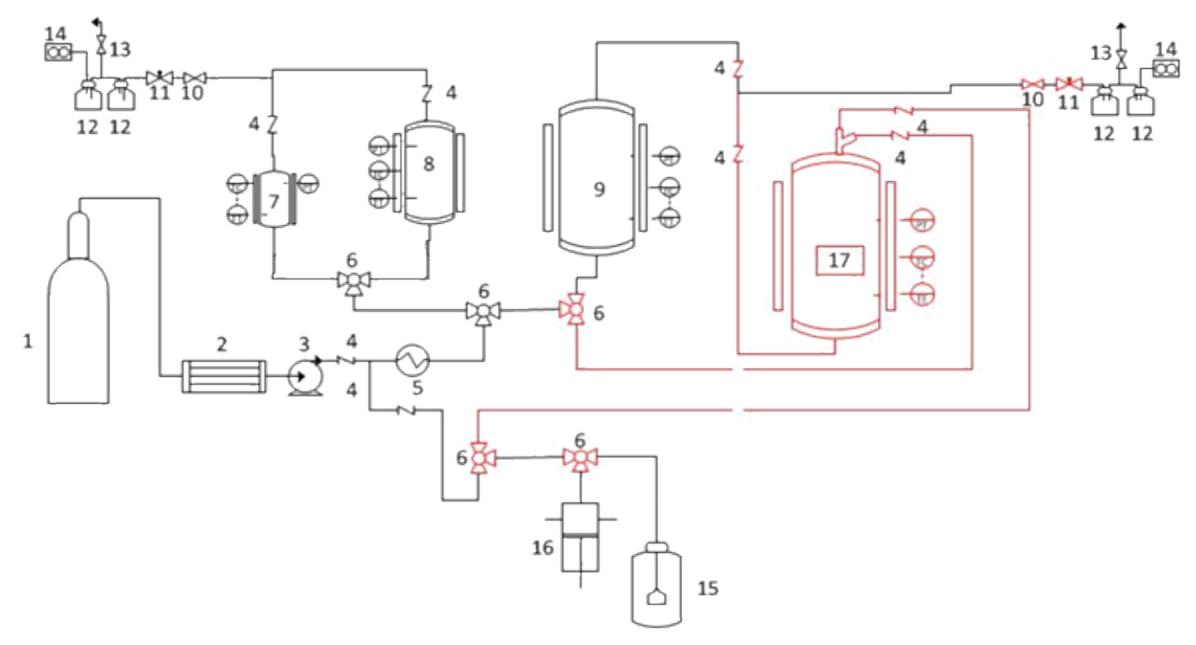

Legenda Fluxograma SAS: indicado em vermelho a adição do processo SAS à unidade de extração por fluido supercrítico. [1] - Cilindro de $\mathrm{CO}_{2}$ com tubo pescador, [2] - trocador de calor, [3] - bomba de alta pressão, [4] válvulas de retenção, [5] - trocador de calor (aquecimento), [6] - válvulas de 3 vias, [7] - vaso de extração 100 $\mathrm{mL}$, [8] - vaso de extração de $500 \mathrm{~mL}$, [9] - vaso de extração $1 \mathrm{~L}$, [10] - válvulas de bloqueio, [11] - válvulas micrométricas, [12] - vasos de separação, [13] - válvulas de segurança, [14] - sensor de vazão, [15] - vaso de cossolvente, [16] - bomba de cossolvente, [17] - vaso de precipitação 2 L, [18] - filtro de aço sinterizado. PT Transmissor de pressão, TT - Transmissor de temperatura, TC - Controlador de temperatura.

Também foi elaborado o projeto em 3D, utilizando o software Solidworks (Figura 3). O emprego deste software permitiu avaliar a disposição dos equipamentos em $3 \mathrm{D}$ no espaço disponível para a introdução do processo SAS, a partir de conhecimento das dimensões definidas para os principais componentes e equipamentos.

A partir do fluxograma proposto e tendo como base o projeto $3 \mathrm{D}$, os equipamentos adquiridos e utilizados na montagem da unidade híbrida foram os seguintes: vaso de precipitação de 2L; filtro de aço sinterizado; válvulas direcionais de 3 vias; válvulas de retenção; válvula de bloqueio e válvula micrométrica.

\subsection{Ensaios Operacionais e Produção de partículas de cafeína}

Para validar a operação do equipamento desenvolvido neste trabalho, realizaram-se experimentos de produção de partículas de cafeína, seguindo as condições de processo 
previamente definidas e seguindo o procedimento definido por Brun et al. (2012). Os resultados obtidos foram avaliados por microscopia (MEV). Na Figura 4 é apresentada a imagem da cafeína previamente ao processamento pelo processo SAS.

Figura 3 - Projeto em 3D da unidade piloto SAS

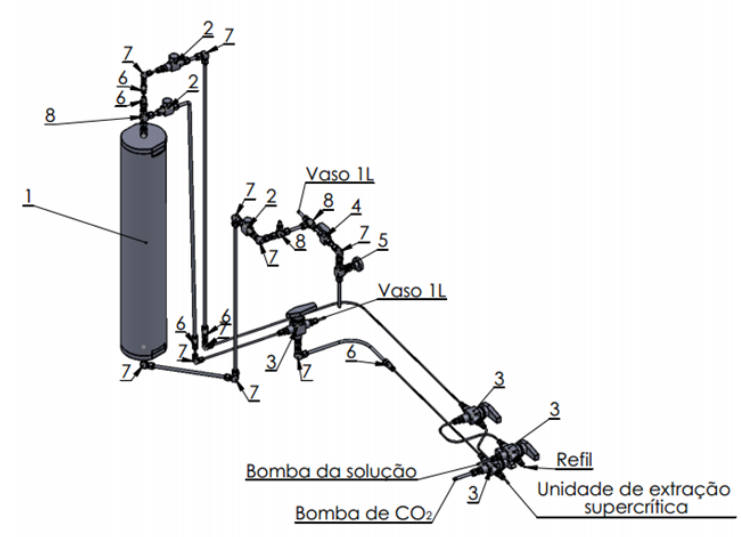

Legenda Projeto 3D: [1] - Vaso de precipitação, [2] - Válvulas de retenção, [3] - Válvulas de 3 vias, [4] Válvula de bloqueio, [5] - Válvula micrométrica, [6] - Redutores, [7] - Joelhos, [8] - Tês.

Figura 4 - Partículas de cafeína não processadas

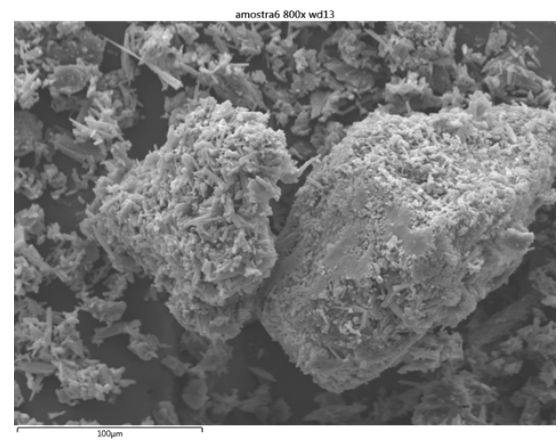

A imagem apresentada na Figura 5 é referente às partículas de cafeína resultantes do uso do processo SAS, seguindo as condições indicadas na metodologia: $\mathrm{P}=100$ bar e $\mathrm{T}=60^{\circ} \mathrm{C}$. $\mathrm{O}$ rendimento em massa de partículas de cafeína produzidas em relação à massa de cafeína utilizada ao processo foi de $73,7 \%(\mathrm{~m} / \mathrm{m})$.

Figura 5 - Partículas de cafeína precipitadas pelo processo SAS na $\mathrm{P}=100$ bar e $\mathrm{T}=60^{\circ} \mathrm{C}$

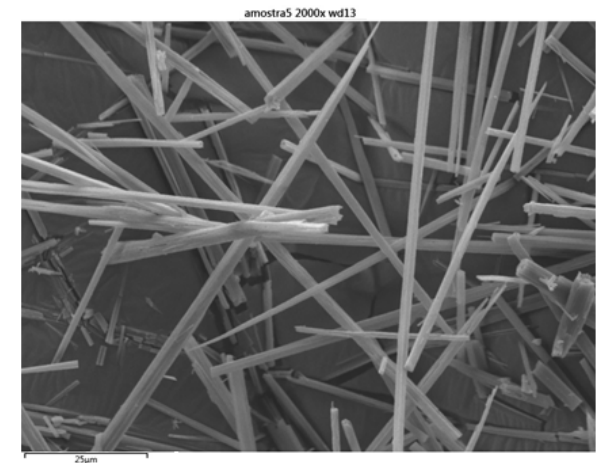


O equipamento desenvolvido funcionou conforme o previamente estabelecido, tanto em relação à obtenção de partículas, quanto na reprodutibilidade. As variáveis de processo se mostraram estáveis, permitindo a operação em diferentes condições operacionais, mantendo a confiabilidade e veracidade das mesmas. A hibridização da unidade piloto de extração supercrítica com a unidade piloto SAS, possibilitou agilidade e economia ao projeto.

\section{CONCLUSÕES}

Tendo como base os resultados obtidos, é possível concluir que o equipamento desenvolvido, montado e testado se mostrou apto para ser utilizado na produção de micro/nanopartículas, apresentando estabilidade, segurança e veracidade nas variáveis de processo.

Houve uma grande diminuição de custos ao se incorporar a unidade SAS à planta piloto de extração supercrítica, criando uma unidade mista que atende a nova tecnologia sem afetar a eficiência da planta pré-existente. O teste realizado com as variáveis de processo de 100 bar e $60^{\circ} \mathrm{C}$ reproduziu os resultados encontrados na literatura (Brun et al., 2012), quanto à morfologia e dimensão das partículas.

\section{REFERÊNCIAS}

AGÊNCIA BRASILEIRA DE DESENVOLVIMENTO INDUSTRIAL (ABDI). Cartilha sobre nanotecnologia. [Campinas], 2011. 60 p. Disponível em: http://www.abdi.com.br/Estudo/Cartilha\%20nanotecnologia.pdf $>$. Acesso em 10 setembro. 2013.

BRISTOW, S.; SHEKUNOV, T.; SHEKUNOV, B. et al. Analysis of the supersaturation and precipitation process with supercritical $\mathrm{CO}_{2}$. The Journal of Supercritical Fluids, v. 21, n. 3, p. 257-271, Nov. 2001.

BRUN, G.W.; MARTÍN, A.; CASSEL, E. et al. Crystallization of Caffeine by Supercritical Antisolvent (SAS) Process:Analysis of Process Parameters and Control of Polymorphism. Crystal Growth \& Design. V. 12, p.1943-1951, 2012.

CARENO, S.; BOUTIN, O.; BADENS, E. Drug recrystallization using supercritical antisolvent (SAS) process with impinging jets: Effect of process parameters. Journal of Crystal Growth, v. 342, n. 1, p. 34-41, Mar. 2012.

CASSEL, E.; BEDINOT, C.; VARGAS, R.M.F. Unidade piloto de extração supercrítica. BR. PROV020110081175, 2011.

TAI, C.; CHENG, C-S. Supersaturation and crystal growth in gas anti-solvent crystallization. Journal of Crystal Growth, v. 183, p. 622 -632, Feb. 1998. 